Canadian

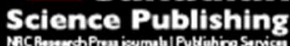

Applied Physiology, Nutrition, and Metabolism Physiologie appliquée, nutrition et métabolisme

\title{
Preliminary safety analysis of High-Intensity Interval Training (HIIT) in persons with chronic stroke
}

\begin{tabular}{|r|l|}
\hline Journal: & Applied Physiology, Nutrition, and Metabolism \\
\hline Manuscript ID & apnm-2016-0369.R1 \\
\hline Manuscript Type: & Article \\
\hline Date Submitted by the Author: & 31 -Aug-2016 \\
\hline Complete List of Authors: & $\begin{array}{l}\text { Carl, Daniel; University of Cincinnati Academic Health Center, } \\
\text { Rehabilitation Sciences } \\
\text { Boyne, Pierce; University of Cincinnati Academic Health Center, } \\
\text { Rehabilitation Sciences } \\
\text { Rockwell, Bradley; University of Cincinnati Academic Health Center, } \\
\text { Rehabilitation Sciences } \\
\text { Gerson, Myron; University of Cincinnati Academic Health Center, Internal } \\
\text { Medicine \& Cardiology } \\
\text { Khoury, Jane; Cincinnati Children's Hospital Medical Center, Biostatistics } \\
\text { Kissela, Brett; University of Cincinnati Academic Health Center, Neurology } \\
\text { \& Rehabilitation Medicine } \\
\text { Dunning, Kari; University of Cincinnati Academic Health Center, } \\
\text { Rehabilitation Sciences }\end{array}$ \\
\hline Keyword: & $\begin{array}{l}\text { stroke < nervous system, High Intensity Interval Training, Rehabilitation, } \\
\text { exercise training < exercise, exercise therapy < exercise }\end{array}$ \\
\hline
\end{tabular}




\section{Preliminary safety analysis of High-Intensity Interval Training (HIIT) in persons with chronic stroke}

Daniel L. Carl PhD ${ }^{1}$; Pierce Boyne PT, DPT, NCS ${ }^{1,2}$; Bradley Rockwell BS ${ }^{1}$; Myron Gerson

$\mathrm{MD}^{3}$; Jane Khoury $\mathrm{PhD}^{2,4}$; Brett Kissela MD, $\mathrm{MS}^{5}$ Kari Dunning $\mathrm{PT}, \mathrm{PhD}^{1,2}$.

${ }^{1}$ Department of Rehabilitation Sciences, College of Allied Health Sciences, University of Cincinnati, Cincinnati, OH

${ }^{2}$ Department of Environmental Health, College of Medicine, University of Cincinnati

${ }^{3}$ Departments of Internal Medicine and Cardiology, College of Medicine, University of Cincinnati

${ }^{4}$ Division of Biostatistics and Epidemiology, Cincinnati Children's Hospital Medical Center, Cincinnati, OH

${ }^{5}$ Department of Neurology and Rehabilitation Medicine, College of Medicine, University of Cincinnati

\section{Please address correspondence to:}

Daniel L. Carl

University of Cincinnati Medical Center, Department of Rehabilitation Sciences

3202 Eden Avenue, Cincinnati OH 45220-0394

E-mail: Daniel.Carl@uc.edu; Fax: 513-558-7474; Phone: 513-885-4158

\section{$\underline{\text { Additional E-mail addresses }}$}

pierce.boyne@uc.edu

rockwebd@mail.uc.edu

gersonml@ucmail.uc.edu

jane.khoury@cchmc.org

kisselbm@ucmail.uc.edu

kari.dunning@uc.edu 


\section{$\underline{\text { Abstract }}$}

Aim: To assess safety via electrocardiographic (ECG), blood pressure (BP), heart rate (HR), and orthopedic responses to 3 different HIIT protocols in persons with stroke.

Methods: 18 participants (10 male; $61.9+8.3$ yo; $5.8+4.2$ y post stroke) completed a symptomlimited stress test (GXT) with ECG monitoring to screen for eligibility and determine HR peak. The 3 HIIT protocols involved repeated $30 \mathrm{~s}$ bursts of treadmill walking at maximum speed alternated with rest periods of $30 \mathrm{~s}$ (P30), $1 \mathrm{~min}$ (P60) or $2 \mathrm{~min}$ (P120). Sessions were performed in random order and included 5 min warm up, 20 min HIIT and 5 min cool down. Variables measured included ECG activity, BP, HR, signs and symptoms of CV intolerance, and orthopedic concerns. Generalized linear mixed models and Tukey-Kramer adjustment were used to compare protocols using $\mathrm{p}<0.05$.

Results: No signs or symptoms of CV intolerance, significant arrhythmias, ST segment changes or orthopedic responses resulted in early termination of any HIIT session. HIIT elicited HR's in excess of $88 \%$ of measured $\mathrm{HR}_{\text {peak }}$ including 6 (P30), 8 (P60) and 2 (P120) participants eliciting

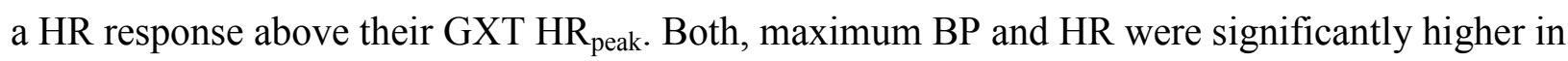
$\mathrm{P} 30$ and P60 relative to $\mathrm{P} 120$.

Conclusion: Preliminary data indicate that persons with chronic stroke who have been prescreened with an ECG stress test, a symptom-limited GXT, and a harness for fall protection; may safely participate in HIIT generating substantially higher HR's than what is seen in traditional moderate intensity training.

$\underline{\text { Key words }}$ Stroke, High-Intensity Interval Training (HIIT), Exercise, and Rehabilitation 


\section{INTRODUCTION}

Approximately 800,000 people are affected by stroke each year in the United States (Roger et al. 2012). Coupled with a 35\% reduction in the mortality rate in the past decade, the number of stroke survivors in need of safe and effective post-stroke rehabilitative care is significant (Go et al. 2014). Approximately 50\% of persons with stroke exhibit hemiparesis, or weakness on one side of the body (Go et al. 2014; Gresham et al. 1979). As a consequence, a majority of persons with stroke have increased fall risk, decreased gait velocity, and exhibit markedly diminished aerobic capacity (Billinger et al. 2012; Billinger et al. 2014; Boyne et al. 2013; Michael et al. 2005). This diminished capacity is related to long-term risk for additional cardiac events and recurrent stroke (Mora et al 2007; Tang et al. 2014). Current post-stroke exercise guidelines recommend moderate-intensity continuous aerobic exercise to enhance motor recovery and improve cardiovascular conditioning (Billinger et al. 2013; Gordon et al. 2004). However, recent evidence suggests that exercise conducted at higher intensities may be more efficacious than moderate-intensity exercise (Boyne et al. 2013; Boyne et al. 2015; Burgomaster et al. 2005; Hornby et al. 2011; Macpherson et al. 2011; Rognmo et al. 2014).

High-intensity interval training (HIIT) is an exercise training strategy that increases the overall time spent at higher intensities by using short bursts of very high intensity exercise interspersed with recovery periods. Original support for HIIT among non-disabled adults included the demonstration of enzymatic activity improvement and performance enhancement similar to that seen with moderate intensity exercise, but with a fraction of the time commitment (Burgomaster et al. 2005; Gibala et al. 2006). Studies involving healthy and clinical populations have since shown that a variety of HIIT protocols are significantly more efficacious than 
moderate-intensity exercise for improving $\mathrm{VO}_{2}$ max, muscular force, muscular peak power and performance (Gibala and McGee 2008; Kessler et al. 2012).

Evidence supporting the use of HIT in specific high-risk clinical populations soon followed (Boyne et al. 2013). For example, Wisloff et al. (2007) demonstrated left ventricular remodeling and improved ejection fraction in patients with heart failure after HIIT while Nytroen et al. (2013) found a reduction in the progression of cardiac allograft vasculopathy in heart transplant patients. In addition, Babraj and colleagues (2009) demonstrated a positive effect from a low-volume HIIT protocol on insulin action and glycemic control in healthy young adults while Little et al. (2011) reported an enhanced post prandial blood glucose response and overall blood glucose control during continuous $24 \mathrm{~h}$ monitoring in persons with type II diabetes mellitus. Among persons with stroke, adding treadmill HIIT to inpatient rehabilitation has been shown to elicit significantly greater improvements in gait recovery (Lau and Mak 2011; Pohl et al. 2002).

Despite the literature supporting HIIT as a clinical rehabilitative strategy, there is limited research on its safety in these populations. For example, previous randomized controlled trials of HIIT in stroke rehabilitation have not reported heart rate (HR) or blood pressure (BP) responses (Lau and Mak 2011; Pohl et al. 2002). With regard to concerns of safety no adverse events were reported in either study. Wisloff et al. (2007) studied high intensity aerobic interval training in persons over the age of 70 and post-infarction and found no adverse events. Rognmo et al. (2012) likewise reported that there was low risk of cardiovascular events after both HIIT and MICE (1 fatal cardiac arrest during 129,456 hours of MICE and 2 nonfatal cardiac arrests during 46,364 hours of HIIT). 
Hypotensive responses following high intensity exercise in healthy male adults and in overweight women have been shown to be both intensity and modality driven (Eicher et al. 2010; Bonsu and Terblanche 2016). Therefore, given the known transient increase in stress on the cardiovascular system associated with increases in training intensity, coupled with the intention of the HIIT protocol design to increase HR's above what would be attained through more traditional forms of aerobic interval training, it is prudent to establish safety guidelines for using HIIT in clinical populations. Specifically, individuals with stroke who tend to present with a wide variety of comorbidities, including a high rate of silent myocardial ischemia (Billinger et al. 2014; Adams et al. 2003). Therefore the purpose of this study was to assess in persons with chronic stroke who have been screened by a symptom-limited GXT, their electrocardiographic (ECG), BP, HR, and orthopedic responses to 3 different HIIT protocols.

\section{METHODS}

\section{Participants}

The study was approved by the University of Cincinnati Institutional Review Board and conducted in a cardiovascular stress laboratory within the university hospital. Participants were recruited from the local community and provided informed consent prior to participation.

\section{Inclusion criteria}

1) age 40-85 years; 2) unilateral stroke experienced $>6$ months prior to enrollment; 3) gait speed $\leq 1.0 \mathrm{~m} / \mathrm{s}$, measured by the 10 meter walk test (Tilson et al. 2010); 4) able to walk 10 meters over ground with assistive devices as needed and no physical assistance; 5) able to walk 3 minutes on the treadmill at $\geq 0.13 \mathrm{~m} / \mathrm{s}(0.3 \mathrm{mph})$ with no aerobic exercise contraindications (ACSM 2014; Macko et al. 2005); 6) stable cardiovascular condition (American Heart 
Association class B, allowing for aerobic capacity $<6$ metabolic equivalents) (Furie et al. 2011; ACSM 2014); 7) not currently participating in formal rehabilitation.

\section{Exclusion criteria}

1) significant resting electrocardiographic (ECG) abnormalities (ACSM 2014); 2)

evidence of myocardial ischemia or significant arrhythmia on treadmill ECG stress test (ACSM 2014); 3) hospitalization for cardiac or pulmonary disease within the prior 3 months; 4) pacemaker or implanted defibrillator; 5) lower extremity claudication; 6) Mini-Mental State Exam $<23 / 30$ (Teng and Chui 1987); 8) severe lower extremity spasticity (Ashworth $\geq 3$ ) (Ashworth 1964); 9) lower extremity weight bearing pain $>4 / 10$ on a visual analogue scale.

\section{Study design}

A single-session crossover design was employed and is described in detail elsewhere (Boyne et al. 2015). Briefly, after a clinical examination and ECG stress test to determine eligibility, each participant performed a second symptom-limited graded exercise test (GXT) to determine peak exercise capacity for heart rate $\left(\mathrm{HR}_{\text {peak }}\right)$ and blood pressure $\left(\mathrm{BP}_{\text {peak }}\right)$. The GXT protocol followed the recommendations of Macko et al. (2005) and involved holding the treadmill speed constant while increasing the grade $2-4 \%$ in two minute increments until test completion. Single sessions of three different treadmill HIIT protocols were then performed in random order with a one week washout period between sessions. All training sessions were conducted at the same time of day as the GXT.

\section{HIIT Protocols}

The 3 HIIT protocols differed based on the length of the recovery periods: 30 seconds (P30), 60 seconds (P60) or 120 seconds (P120). No stroke-specific data were previously available to guide in the selection of the recovery times. Therefore the HIIT protocol was 
designed to maximize training intensity and the number of steps taken; both previously shown to enhance aerobic capacity (Lam et al. 2010; Globas et al. 2012). Upon completion of a successful training burst, treadmill speed was increased by $0.1 \mathrm{mph}$ for the next burst. When a participant exhibited a mechanical fault, speed was decreased by $0.1 \mathrm{mph}$ for the next burst. During recovery, participants were given the option to stand still, march in place or sit, similar to previous studies (Burgomaster et al. 2005; Gibala et al. 2006). Each HIIT protocol included a 5 minute warm up (30-50\% $\left.\mathrm{VO}_{2 \text { peak }}\right)$, up to 20 minutes of HIIT, and a 5 minute cool down (30$\left.50 \% \mathrm{VO}_{2 \text { peak }}\right)$. The HIIT portion of each session was continued until each participant completed the HIIT session or reached volitional fatigue. ECG activity, HR, BP, and other signs or symptoms of cardiorespiratory insufficiency, worsening neurologic impairments or orthopedic injury were monitored for safety, using accepted stopping criteria (ACSM 2014; Fletcher et al. 2013). Participants wore a harness secured to an overhead support system for fall protection during all HIIT sessions. Participants were allowed use of the handrail for balance and wore their habitual orthotic devices. No physical assistance was provided.

\section{Outcome Measures}

\section{Myocardial Arrhythmia and Ischemia Monitoring}

A 12-lead ECG was donned and continuously monitored for arrhythmia, aberrancy and any signs of ischemia during the stress test, $\mathrm{HR}_{\text {peak }}$ test and for every HIIT session (Fletcher et al. 2013). Significant arrhythmia was defined as ventricular tachycardia, ventricular fibrillation or 3 or more multiform premature ventricular contractions in a span of 10 beats (Marzolini et al. 2012). Evidence of ischemia was defined as more than $1 \mathrm{~mm}$ of depression at 60 to $80 \mathrm{~ms}$ past the J point and/or angina (Fletcher et al. 2013). ECG monitoring continued following the GXT and each HIIT session with the participant in a seated position until resting HR recovered below 
100 beats per minute. Participants were also monitored for signs of stress or discomfort including pallor, cyanosis and angina.

\section{Hypotensive Response Monitoring}

Minimum BP during HIIT was determined for each session and defined as an initial increase followed by a subsequent drop of $20 \mathrm{~mm} \mathrm{Hg}$ or greater. In addition, the difference between minimum HIIT BP and resting BP was obtained as an index of potential hypotensive responses (negative values would indicate that BP dropped below the resting level during HIIT) (Le et al. 2008). Following each HIIT session the final BP response was measured with the participant in the seated position after their recovery HR dropped below 100 beats per minute. To further test for hypotensive responses, participants were asked to rate any sensations of nausea and lightheadedness on a 10 point visual analogue scale after each session.

\section{Orthopedic Safety Monitoring}

Participants were closely monitored at all times for any occurrence of orthopedic injury (e.g. fall, ankle sprain). The number of times the fall protection harness was engaged was recorded during each HIIT session. Participants were asked to rate any sensations of pain on a 10 point visual analogue scale before and after each session. Cardiovascular Intensity Peaks

HR was recorded continuously by the ECG during every HIIT session. Maximal HR and an individual's ability to exceed $\mathrm{HR}_{\text {peak }}$ from the GXT were identified. Age-predicted $\mathrm{HR}_{\text {peak }}$ was also determined to provide additional insight and clarity to the intensity of the HIIT protocols in the stroke population. The following formulas were used accordingly:

$$
\begin{aligned}
& \text { APmax-HR }=164-(0.7 \mathrm{x} \text { age })[\text { subjects on heart rate limiting medications] }(\text { Brawner et al. 2004) } \\
& \text { APmax-HR }=206.9-(0.67 \mathrm{x} \text { age }) \text { [all other subjects }] \text { (Gellish et al. 2007). }
\end{aligned}
$$

BP was measured manually with a sphygmomanometer before exercise, immediately after the first burst, at the end of the recovery period nearest the $5^{\text {th }}$ minute of exercise, at minute 10 and 
after the last completed burst. The upper BP limit was set at $220 \mathrm{~mm} \mathrm{Hg}$ systolic and $115 \mathrm{~mm} \mathrm{Hg}$ diastolic (Gordon et al. 2009) and maximal BP was determined for each session on an individual basis.

\section{Statistics}

Continuous variables were described by means, $95 \%$ confidence intervals ( $95 \% \mathrm{CI})$ and ranges, while categorical variables were described by frequencies and proportions. Generalized linear mixed models were used to compare safety measures between HIIT protocols, using participant as a random effect to account for the repeated nature of the data. The appropriate distribution and link functions were employed, dependent upon the nature of the outcome variable; normal and identity for continuous, binary and logit for dichotomous, and negative binomial and log for the count; an unstructured covariance matrix was used. When the overall model was significant, pairwise tests were obtained using Tukey-Kramer adjustment for multiple comparisons. SAS v9.3 (SAS, Inc., Cary, NC) was used for analysis. The significance level was set at 0.05 .

\section{RESULTS}

Of the 22 participants who consented for the study, 3 were excluded for not meeting eligibility criteria as follows: $1.5 \mathrm{~mm}$ of asymptomatic ST depression during stress test $(\mathrm{n}=1)$, resting ST depression that would have made a stress test uninterpretable $(n=1)$, and lower extremity pain of $8 / 10$ with gait $(n=1)$. One additional participant was lost to follow up after one HIIT session due to personal reasons not related to the study. Thus, 18 participants successfully completed the study. Their demographics, gait and clinical characteristics are shown in Table 1.

INSERT TABLE 1 HERE 


\section{Myocardial Arrhythmia and Ischemia Monitoring}

Continuous ECG monitoring found no significant arrhythmia, new aberrancy or signs of myocardial ischemia during any HIIT session. Likewise, continuous participant observation found no pallor or cyanosis, and participant questioning found no evidence of angina.

\section{Hypotensive Response Monitoring}

One participant (out of 18) exhibited a clinically significant hypotensive response with a systolic BP drop of $24 \mathrm{~mm} \mathrm{Hg}$ below resting at the end of a recovery period during P120 (98/76 vs $122 / 80 \mathrm{~mm} \mathrm{Hg}$ resting) (Table 2 ). The participant was asymptomatic and was able to complete the session without incident. A different participant reported $1 / 10$ on the analogue scale for lightheadedness when questioned after successfully finishing P60. This participant did not exhibit a corresponding drop in BP (130/90 vs 120/84 mm Hg resting), was otherwise asymptomatic and reported that the lightheadedness only occurred briefly during the session.

\section{INSERT TABLE 2 HERE}

\section{Orthopedic Safety Monitoring}

Continuous observation found no orthopedic injuries and no participants reported new pain before or after any session (Table 3). Four of 18 participants engaged the fall protection harness on at least one occasion. One of these participants engaged the harness 14 times (8 during P30; 2 during P60; 4 during P120). The other three participants engaged the harness 1 time each (1 during P30; 2 during P60).

\section{INSERT TABLE 3 HERE}

\section{Cardiovascular Intensity Peaks}


Individual HR responses for all three protocols are shown in Figures 1 and 2. On average, the maximal HRs elicited during P30, P60 and P120 were 130, 127 and 117 bpm, respectively (Table 4). These HRs represented $97 \%, 95 \%$ and $88 \%$ of $\mathrm{HR}_{\text {peak }}$ from the GXT and $78 \%, 77 \%$ and $71 \%$ of age-predicted $\mathrm{HR}_{\max }$ P 30 and P60 had significantly higher HR intensity peaks than P120. The proportion of participants who exceeded their $\mathrm{HR}_{\text {peak }}$ from the GXT was 6/18 for P30, 8/18 for P60 and 2/18 for P120. No participants exceeded age-predicted AP-HR $\max$.

On average, the maximal BPs elicited during P30, P60 and P120 were 159/97, 160/99 and 149/87 mm Hg, respectively. The systolic BPs represented 97\%, 99\% and 91\% of $\mathrm{BP}_{\text {peak }}$ from the GXT. One participant approached the systolic BP cutoff of $220 \mathrm{~mm} \mathrm{Hg}$ during P30 and P60, but was maintained at $210 \mathrm{~mm} \mathrm{Hg}$ by decreasing the treadmill speed during bursts.

\section{INSERT FIGURES $1 \& 2$ and TABLE 4 HERE}

\section{DISCUSSION}

The primary findings from this study were that in individuals pre-screened with ECG stress testing, HIIT was not associated with any signs of significant arrhythmia, myocardial ischemia, uncontrollable hypertension, symptomatic hypotensive responses or orthopedic injury among 18 persons with chronic stroke. Therefore, the incidence proportions for these variables were 0 serious adverse events (AE) per 18 participants and 54 HIIT sessions. Based on these preliminary findings, HIIT appears to be a reasonably safe training methodology in persons with chronic stroke when appropriate precautions including eligibility criteria screening, a GXT with ECG monitoring, and a harness for fall protection are implemented. It is important to note that 2 participants were excluded from participation in the HIIT sessions based on the results of baseline ECG screening, while a third participant was excluded due to baseline orthopedic pain. 
Also noteworthy is that our participants included one who had previously undergone a coronary artery bypass grafting (CABG), two with known heart valve issues, and two participants with a previous myocardial infarction (MI). In addition, 5 of the 18 participants were on HR limiting medications and were able to successfully participate in all 3 HIIT protocols.

\section{Cardiovascular Intensity Peaks}

With vigorous exercise there is an acute and transient increase in the risk for a significant cardiovascular event (Mittleman et al. 1993; Giri et al. 1999). This risk is increased in the presence of cardiovascular disease and especially silent myocardial ischemia, which has a reported $20-40 \%$ prevalence among persons with stroke (Adams et al. 2003). Therefore, the American Heart Association recommends ECG stress testing prior to aerobic exercise for persons with stroke (Billinger et al. 2014), to screen for ischemia. In the current study, the maximum training HR during each of the HIIT protocols averaged $88-97 \%$ of $\mathrm{HR}_{\text {peak }}$ obtained during the baseline symptom-limited GXT, thus indicating high aerobic intensities. During the HIIT sessions, 6 (P30), 8 (P60) and 2 (P120) participants achieved training HRs greater than

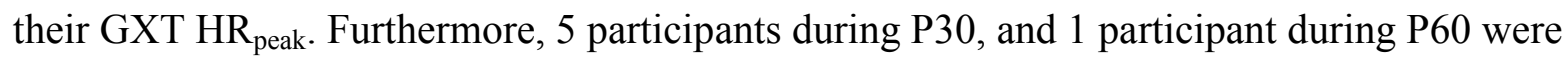
able to sustain their exercise training $\mathrm{HR}$ above their recorded $\mathrm{GXT} \mathrm{HR}_{\text {peak }}$ for a duration longer than 1 minute. In addition, 7 (P30), and 3 (P60) participants were not able to complete their full 20 minute HIIT session due to volitional fatigue. While this shows promise for post-stroke HIIT to allow higher training intensities than are possible with continuous exercise, it also presents a safety concern. It is possible that future patients might have ischemia during HIIT that was not observed during a baseline stress test if the HR during HIIT exceeds the HR from the stress test. There are at least 3 possible ways to address this problem: 1) new methods of stress testing could be developed to elicit higher HRs for persons with stroke; 2) HR during HIIT could be limited to 
that achieved during the stress test by decreasing burst intensity or increasing recovery duration; or 3) ECG monitoring could be continued during HIIT (similar to the current study) until it is apparent that there will be no further increases in training HR.

Current post-stroke exercise guidelines recommend a systolic BP (SBP) hypertensive response cutoff of $250 \mathrm{~mm} \mathrm{Hg}$ for termination of exercise testing or training (ACSM 2014). Our protocol cutoff was set at a conservative value of $220 \mathrm{~mm} \mathrm{Hg}$, based on previous post-stroke exercise guidelines which were in place when the study began (Gordon et al. 2004). The maximum SBP recorded within any of our sessions was $210 \mathrm{~mm} \mathrm{Hg}$ and was measured on two occurrences in the same participant. Decreasing the treadmill speed during bursts allowed us to maintain his BP below $220 \mathrm{~mm} \mathrm{Hg}$ throughout the session. Increased recovery duration was another potential option to limit the hypertensive response but was not used for this study because recovery duration was the independent variable of interest. The highest diastolic BP (DBP) recorded during any session was $112 \mathrm{~mm} \mathrm{Hg}$, which was approaching but still below the recommended cutoff of $115 \mathrm{~mm} \mathrm{Hg}$ (ACSM 2014). These findings reinforce the importance of BP measurement during post-stroke HIIT and demonstrate the feasibility of maintaining BP control in the case of hypertensive responses.

\section{Hypotensive Response Monitoring}

We were concerned that HIIT may heighten a negative, acute post-exercise BP response. Exercise in general has been shown in some of the population to have a transient pressure undershoot as the result of a sudden perfusion of previously occluded muscle (MacDougall et al. 1985; MacDonald 2002) or from excessive blood pooling in the legs. P120 had significantly greater decreases in SBP during recovery and one participant had a SBP drop of $24 \mathrm{~mm} \mathrm{Hg}$ 
below resting BP during the P120 session. However, this participant had an appropriate SBP increase of $28 \mathrm{~mm} \mathrm{Hg}$ during P120 bursts, normal DBP, HR and ECG responses, and was asymptomatic. Another participant reported transient 1/10 lightheadedness during P60 upon questioning after the session. However, this participant had no other signs or symptoms suggestive of a hypotensive response. These findings indicate that hypotensive responses are important to monitor, and may be more likely in protocols with longer passive recovery, but are not a major concern for these post-stroke HIIT protocols.

\section{Orthopedic Safety}

Increases in gait speed may introduce new movement patterns and therefore new tissue stresses not incurred since before the stroke. During screening, we did exclude 1 participant who reported 8/10 lower extremity pain with walking. No participants had increased pain or orthopedic injury during HIIT and no participants requested to discontinue a session for any reason other than fatigue. Although 4 participants did engage the safety harness on at least one occasion, each was able to complete all training protocols and no participants fell. These findings reinforce the need for orthopedic screening and a safety harness during post-stroke HIIT.

\section{Limitations}

The primary weakness of this study is the limitation in generalizability due to small sample size. Serious adverse events during aerobic exercise are very rare events, even for persons with heart disease (ACSM 2014). Therefore, if HIIT continues to show positive outcomes in stroke rehabilitation, large scale monitoring studies will be needed to definitively test safety compared to conventional approaches. In the meantime, investigators should systematically collect and report AE data so that risks and benefits can be appropriately weighed. 
It should be noted that our protocol involved only treadmill training and included a baseline physical examination by a physical therapist, a GXT reviewed by a cardiologist a safety harness, ECG, BP monitoring and continuous close observation during each session. We suggest that future studies of post-stroke HIIT should employ similar safety precautions and monitoring. Another potential limitation is that our participants completed only 3 sessions of HIIT. Additional therapy sessions or training dosage may increase the risk of orthopedic injury or a cardiovascular event.

\section{Conclusions}

Following safety screening including an ECG monitored stress test and ECG monitored training sessions, 3 HIIT protocols were not associated with any signs of cardiac insufficiency, symptomatic hypertensive or hypotensive responses, or orthopedic injury among 18 participants with chronic stroke. Therefore, post-stroke HIIT appears to be reasonably safe for further study, if the precautions and guidelines established are followed. Previous data and observed responses suggest that orthopedic and cardiac screening are needed prior to post-stroke HIIT and that a safety harness, ECG, BP measurement and close observation are needed during training. The authors report no conflicts of interest associated with this manuscript.

\section{Disclosure of funding}

This research was supported in part with a Magistro Family Foundation Research Grant and a Promotion of Doctoral Studies Scholarship from the Foundation for Physical Therapy and by an award from the University of Cincinnati Provost's Pilot Research Program. 


\section{$\underline{\text { References }}$}

Adams R.J., Chimowitz M.I., Alpert J.S., Awad I.A., Cerqueria M.D., Fayad P., et al. 2003. Stroke Council and the Council on Clinical Cardiology of the American Heart Association, American Stroke Association. Coronary risk evaluation in patients with transient ischemic attack and ischemic stroke: a scientific statement for healthcare professionals from the Stroke Council and the Council on Clinical Cardiology of the American Heart Association/American Stroke Association. Circulation, 108(10): 1278-90. doi: 10.1161/01. PMID: 12963684

ACSM's Guidelines for Exercise Testing and Prescription / American College of Sports Medicine. 2014. Editor L. Pescatello. 9th ed. Philadelphia: Wolters Kluwer/Lippincott Williams \& Wilkins Health.

Ashworth B. 1964. Preliminary Trial of Carisoprodol in Multiple Sclerosis. Practitioner, 192: 540-2. PMID: 14143329

Babraj J.A., Vollaard N.B., Keast C., Guppy F.M., Cottrell G., Timmons J.A. 2009. Extremely short duration high intensity interval training substantially improves insulin action in young healthy males. BMC Endocr. Disord. 9:3. doi: 10.1186/1472-6823-9-3. PMID: 19175906

Brawner C.A., Ehrman J.K., Schairer J.R., Cao J.J., Keteyian S.J. 2004. Predicting maximum heart rate among patients with coronary heart disease receiving beta-adrenergic blockade therapy. Am. Heart J. 148(5):910-914. doi: 10.1016/j.ahj.2004.04.035. PMID: 15523326

Billinger S.A., Coughenour E., Mackay-Lyons M.J., Ivey F.M. 2012. Reduced cardiorespiratory fitness after stroke: biological consequences and exercise-induced adaptations. Stroke Res. Treat. 2012: 959120. doi: 10.1155/2012/959120. PMID: 21876848 
Billinger S.A., Arena R., Bernhardt J., Eng J.J., Franklin B.A., Johnson C.M., et al. 2014. American Heart Association Stroke Council, Council on Cardiovascular and Stroke Nursing, Council on Lifestyle and Cardiometabolic Health, Council on Epidemiology and Prevention, and Council on Clinical Cardiology. Physical activity and exercise recommendations for stroke survivors: a statement for healthcare professionals from the American Heart Association/American Stroke Association. Stroke. 45(8): 2532-5345. doi:

10.1161/STR.0000000000000022. PMID: 24846875

Bonsu, B. \& Terblanche, E. 2016. The training and detraining effect of high-intensity interval training on post-exercise hypotension in young overweight/obese women. Eur. J. Appl. Physiol. 116: 77. doi: 10.1007/s00421-015-3224-7. PMID: 26293124

Boyne P., Dunning K., Carl D., Gerson M., Khoury J., Kissela B. 2013. High-intensity interval training in stroke rehabilitation. Top. Stroke Rehabil. 20(4): 317-30. doi: 10.1310/tsr2004-317. PMID: 23893831

Boyne P., Dunning K., Carl D., Gerson M., Khoury J., Kissela B. 2015. Within-session responses to high-intensity interval training in chronic stroke. Med. Sci. Sports Exerc. 47(3): 476-84. doi: 10.1249/MSS.0000000000000427. PMID: 24977698

Burgomaster K.A., Hughes S.C., Heigenhauser G.J., Bradwell S.N., Gibala M.J. 2005. Six sessions of sprint interval training increases muscle oxidative potential and cycle endurance capacity in humans. J. Appl. Physiol. 98(6): 1985-90. DOI: 10.1152/japplphysiol.01095. PMID: 15705728 
Eicher J.D., Maresh C.M., Tsongalis G.J., Thompson P.D., Pescatello L.S. 2010. The additive blood pressure lowering effects of exercise intensity on post-exercise hypotension. Am. Heart J. 160(3):513-20. doi: 10.1016/j.ahj.2010.06.005. PMID: 20826261

Fletcher G.F., Ades P.A., Kligfield P., Arena R., Balady G.J., Bittner V.A., et al. 2013. American Heart Association Exercise, Cardiac Rehabilitation, and Prevention Committee of the Council on Clinical Cardiology, Council on Nutrition, Physical Activity and Metabolism, Council on Cardiovascular and Stroke Nursing, and Council. Exercise standards for testing and training: a scientific statement from the American Heart Association. Circulation, 128(8): 873-934. doi: 10.1161/CIR.0b013e31829b5b44. PMID: 23877260

Furie K.L., Kasner S.E., Adams R.J., Albers G.W., Bush R.L., Fagan S.C., et al. 2011. Guidelines for the prevention of stroke in patients with stroke or transient ischemic attack: a guideline for healthcare professionals from the American Heart Association/American Stroke Association. Stroke. 42(1): 227-276. doi: 10.1161/STR.0b013e3181f7d043. PMID: 20966421

Gellish R.L., Goslin B.R., Olson R.E., McDonald A., Russi G.D., Moudgil V.K. 2007. Longitudinal modeling of the relationship between age and maximal heart rate. Med. Sci. Sports Exerc. 39(5):822-829. doi: 10.1097/mss.0b013e31803349c6. PMID: 17468581

Gibala M.J., McGee S.L. 2008. Metabolic adaptations to short-term high-intensity interval training: a little pain for a lot of gain? Exerc. Sport Sci. Rev. 36(2): 58-63. doi: 10.1097/JES.0b013e318168ec1f. PMID: 18362686

Gibala M.J., Little J.P., van Essen M., Wilkin G.P., Burgomaster K.A., Safdar A. 2006. Shortterm sprint interval versus traditional endurance training: similar initial adaptations in human 
skeletal muscle and exercise performance. J. Physiol. 575(Pt 3): 901-11. doi:

10.1113/jphysiol.2006.112094. PMID: 16825308

Giri S., Thompson P., Kiernan F., Clive J., Fram D.B., Mitchel J.F., et al. 1999. Clinical and angiographic characteristics of exertion-related acute myocardial infarction. JAMA. 282(18): 1731-6. PMID: 10568645

Globas C., Becker C., Cerny J., Lam J.M., Lindemann U., Forrester L.W., et al. 2012. Chronic stroke survivors benefit from high-intensity aerobic treadmill exercise: a randomized control trial. Neurorehabil. Neural Repair, 26:85-95. doi: 10.1177/1545968311418675. PMID: 21885867

Go A.S., Mozaffarian D., Roger V.L., Benjamin E.J., Berry J.D., Blaha M.J., et al. 2014. American Heart Association Statistics Committee and Stroke Statistics Subcommittee. Heart disease and stroke statistics_-2014 update: a report from the American Heart Association. Circulation, 129(3): 399-410. doi: 10.1161/01.cir.0000442015.53336.12. PMID: 24446411

Gordon N.F., Gulanick M., Costa F., Fletcher G., Franklin B.A., Roth E.J., et al. 2004. Physical activity and exercise recommendations for stroke survivors: an American Heart Association scientific statement from the Council on Clinical Cardiology, Subcommittee on Exercise, Cardiac Rehabilitation, and Prevention; the Council on Cardiovascular Nursing; the Council on Nutrition, Physical Activity, and Metabolism; and the Stroke Council. Circulation, 109: 20312041. doi: 10.1161/01.CIR.0000126280.65777.A4. PMID: 15117863

Gresham G.E., Phillips T.F., Wolf P.A., McNamara P.M., Kannel W.B., Dawber T.R. 1979. Epidemiologic profile of long-term stroke disability: the Framingham Study. Arch. Phys. Med. Rehabil. 60(11): 487-491. PMID: 508073 
Hornby T.G., Straube D.S., Kinnaird C.R., Holleran C.L., Echauz A.J., Rodriguez K.S., et al. 2011. Importance of specificity, amount, and intensity of locomotor training to improve ambulatory function in patients poststroke. Top. Stroke Rehabil. 18(4): 293-307. doi: 10.1310/tsr1804-293. PMID: 21914594

Kessler H.S., Sisson S.B. and K.R. Short. 2012. The Potential for High-Intensity Interval Training to Reduce Cardiometabolic Disease Risk. Sports Med. 42(6): 489-509. doi: 10.2165/11630910-000000000-00000. PMID: 22587821

Lam J.M., Globas C., Cerny J., Hertler B., Uludag K., Forrester L.W., et al. 2010. Predictors of response to treadmill exercise in stroke survivors. Neurorehabil. Neural Repair, 24:567-574. doi: 10.1177/1545968310364059. PMID: 20453154

Lau K.W., Mak M.K. 2011. Speed-dependent treadmill training is effective to improve gait and balance performance in patients with sub-acute stroke. J. Rehabil. Med. 43(8): 709-13. doi: 10.2340/16501977-0838. PMID: 21698340

Le V.V., Mitiku T., Sungar, G., Myers J., Froelicher V. 2008. The blood pressure response to dynamic exercise testing: a systematic review. Prog. Cardiovasc. Dis. 51.2: 135-60. doi: 10.1016/j.pcad.2008.07.001. PMID: 18774013

Little J.P., Gillen J.B., Percival M., Safdar A., Tarnopolsky M.A., Punthakee Z., et al. 2011. Low-volume high intensity interval training reduces hyperglycemia and increases muscle mitochondrial capacity in patients with type 2 diabetes. J. Appl. Physiol. 111(6): 1554-60. doi: 10.1152/japplphysiol.00921. PMID: 21868679 
MacDonald, J.R. 2002. Potential causes, mechanisms, and implications of post exercise hypotension J. Hum. Hypertens. 16(4): 225-236. doi: 10.1038/sj.jhh.1001377. PMID: 11967715

MacDougall J.D., Tuxen D., Sale D.G., Moroz J.R., Sutton J.R. 1985. Arterial blood pressure response to heavy resistance exercise. J. Appl. Physiol. 58(3): 785-790. PMID: 3980383

Macko R.F., Ivey F.M., Forrester L.W. 2005 Task-oriented aerobic exercise in chronic hemiparetic stroke: training protocols and treatment effects. Top. Stroke Rehabil. 12(1): 45-57. doi: 10.1310/PJQN-KAN9-TTVY-HYQH. PMID: 15736000

Macpherson R.E., Hazell T.J., Olver T.D., Paterson D.H., Lemon P.W. 2011. Run sprint interval training improves aerobic performance but not maximal cardiac output. Med. Sci. Sports Exerc. 43(1):115-22. doi: 10.1249/MSS.0b013e3181e5eacd. PMID: 20473222

Marzolini S., Paul O., McIlroy., Brooks D. 2012. The feasibility of cardiopulmonary exercise testing for prescribing exercise to people after stroke. Stroke, 43(4): 1075-1081. doi:

10.1161/STROKEAHA.111.635128. PMID: 22328554

Michael K.M., Allen J.K., Macko R.F. 2005. Reduced ambulatory activity after stroke: the role of balance, gait, and cardiovascular fitness. Arch. Phys. Med. Rehabil. 86(8):1552-1556. doi: 10.1016/j.apmr.2004.12.026. PMID: 16084807

Mittleman M., Maclure M., Tofler G., Sherwood J.B., Goldberg R.J., Muller J.E.1993. Triggering of acute myocardial infarction by heavy physical exertion. Protection against triggering by regular exertion. Determinants of Myocardial Infarction Onset Study Investigators. N. Engl. J. Med. 329(23): 1677-83. doi: 10.1056/NEJM199312023292301. PMID: 8232456 
Mora S., Cook N., Buring J.E., Ridker P.M., Lee I.M. 2007. Physical activity and reduced risk of cardiovascular events: Potential mediating mechanisms. Circulation, 116(19): 2110-18. doi: 10.1161/CIRCULATIONAHA.107.729939. PMID: 17967770

Nytrøen K., Rustad L.A., Erikstad I., Aukrust P., Ueland T., Lekva T., et al. 2013. Effect of highintensity interval training on progression of cardiac allograft vasculopathy. J. Heart Lung Transplant, 32(11): 1073-80. doi: 10.1016/j.healun.2013.06.023. PMID: 23906899

Pohl M., Mehrholz J., Ritschel C., Ruckriem S. 2002. Speed-Dependent Treadmill Training in Ambulatory Hemiparetic Stroke Patients: A Randomized Controlled Trial. Stroke, 33(2): 553-8. PMID: 11823669

Roger V.L., Go A.S., Lloyd-Jones D.M., Benjamin E.J., Berry J.D., Borden W.B., et al. 2012. American Heart Association Statistics Committee and Stroke Statistics Subcommittee. Heart disease and stroke statistics_-2012 update: a report from the American Heart Association. Circulation, 125(1): e2-e220. doi: 10.1161/CIR.0b013e31823ac046. PMID: 22179539

Rognmo O., Hetland E., Helgerud J., Hoff J., Slørdahl S.A. 2004. High intensity aerobic interval exercise is superior to moderate intensity exercise for increasing aerobic capacity in patients with coronary artery disease. Eur. J. Cardiovasc. Prev. Rehabil. 11(3): 216-22. PMID: 15179103

Rognmo O., Moholdt T., Bakken H., Hole T., Mølstad P., Myhr N.E., et al. 2012. Cardiovascular risk of high- versus moderate-intensity aerobic exercise in coronary heart disease patients. Circulation, 126: 1436-40. doi: 10.1161/CIRCULATIONAHA.112.123117. PMID: 22879367

Tang A., Eng J.J., Brasher P.M., Madden K.M., Mohammadi A., Krassioukov A.V., et al. 2014. Physical activity correlates with arterial stiffness in community-dwelling individuals with stroke. 
J. Stroke Cerebrovasc. Dis. 23(2): 259-66. doi: 10.1016/j.jstrokecerebrovasdis.2013.01.020.

PMID: 23473623

Teng E. and H. Chui. 1987. The Modified Mini-Mental State (3MS) examination. J. Clin Psychiatry. 48(4): 314-318. PMID: 3611032

Tilson J.K., Sullivan K.J., Cen S.Y., Rose D.K., Koradia C.H., Azen S.P., et al. 2010. Locomotor Experience Applied Post Stroke (LEAPS) Investigative Team. Meaningful gait speed improvement during the first 60 days poststroke: minimal clinically important difference. Phys. Ther. 90(2): 196-208. doi: 10.2522/ptj.20090079. PMID: 20022995

Wisloff U., Stoylen A., Loennechen J.P., Bruvold M., Rognmo Ø., Haram P.M., et al. 2007. Superior cardiovascular effect of aerobic interval training versus moderate continuous training in heart failure patients: a randomized study. Circulation, 115(24): 3086-3094. DOI:

10.1161/CIRCULATIONAHA.106.675041. PMID: 17548726 
Table 1. Participant Characteristics $(\mathrm{N}=18)$

\begin{tabular}{|c|c|c|}
\hline \multicolumn{3}{|c|}{ Descriptive measures, n (\%) } \\
\hline \multicolumn{2}{|c|}{ Male } & $10(56 \%)$ \\
\hline \multicolumn{2}{|l|}{ Age } & $61.9(8.3)[48.9,82.2]$ \\
\hline \multicolumn{3}{|l|}{ Race } \\
\hline & Caucasian & $13(72 \%)$ \\
\hline & African American & $5(28 \%)$ \\
\hline \multicolumn{3}{|c|}{ Stroke type } \\
\hline & Ischemic & $16(89 \%)$ \\
\hline & Hemorrhagic & $2(11 \%)$ \\
\hline \multicolumn{3}{|c|}{ Cardiovascular measures, $\mathrm{n}(\%)$} \\
\hline \multirow{2}{*}{\multicolumn{3}{|c|}{\begin{tabular}{l} 
Cardiac history \\
\multicolumn{1}{l}{ Coronary artery disease }
\end{tabular}}} \\
\hline & Coronary artery disease & \\
\hline & Myocardial infarction & $2(11 \%)$ \\
\hline & Coronary artery bypass grafting & $1(6 \%)$ \\
\hline & Valve surgery & $2(11 \%)$ \\
\hline \multicolumn{3}{|c|}{ Cardiovascular risk factors } \\
\hline & Hypertension & $9(50 \%)$ \\
\hline & Hypercholesterolemia & $14(78 \%)$ \\
\hline & Current Smoker & $3(17 \%)$ \\
\hline & Diabetes Mellitus & $2(11 \%)$ \\
\hline & Taking a beta blocker & $5(28 \%)$ \\
\hline \multicolumn{3}{|c|}{ Orthopedic measures, $\mathbf{n}(\%)$} \\
\hline LEFM m & tor score $(0-34)$ & $24.2(5.6)(11-34)$ \\
\hline \multicolumn{3}{|c|}{ Habitual assistive device } \\
\hline & None & $3(17 \%)$ \\
\hline & Single point cane & $10(56 \%)$ \\
\hline & Small base quad cane & $2(11 \%)$ \\
\hline & Large base quad cane & $2(11 \%)$ \\
\hline & Rolling walker & $1(6 \%)$ \\
\hline \multicolumn{3}{|c|}{ Habitual orthotic device } \\
\hline & None & $7(39 \%)$ \\
\hline & Ankle foot orthosis & $8(44 \%)$ \\
\hline & Foot drop stimulator & $2(11 \%)$ \\
\hline & Ankle inversion splint & $1(6 \%)$ \\
\hline \multicolumn{3}{|c|}{ Functional Ambulation Category } \\
\hline & Dependent on supervision & $5(28 \%)$ \\
\hline & Independent on level surfaces & $5(28 \%)$ \\
\hline & Independent & $8(44 \%)$ \\
\hline & Wheelchair use & $5(28 \%)$ \\
\hline \multicolumn{3}{|c|}{ Gait speed measures, n (\%) } \\
\hline \multicolumn{2}{|c|}{ Comfortable overground gait speed $\mathrm{m} / \mathrm{s}$} & $0.60(0.29)[0.19,0.96]$ \\
\hline \multicolumn{2}{|c|}{ Fastest overground gait speed m/s } & $0.76(0.40)[0.19,1.34]$ \\
\hline \multicolumn{2}{|c|}{ Starting HIIT treadmill speed $\mathrm{m} / \mathrm{s}$} & $0.84(0.32)[0.22,1.39]$ \\
\hline \multicolumn{3}{|c|}{ Medications, n (\%) } \\
\hline \multicolumn{2}{|c|}{$\alpha_{1}$ Blocker } & $2(11 \%)$ \\
\hline \multicolumn{2}{|c|}{$\beta_{1}$ Blocker } & $5(28 \%)$ \\
\hline Calcium $^{+}$ & Channel Blocker & $4(22 \%)$ \\
\hline
\end{tabular}




\begin{tabular}{|l|l|}
\hline Diuretic & $4(22 \%)$ \\
\hline ACE Inhibitor & $5(28 \%)$ \\
\hline Anticoagulant & $16(89 \%)$ \\
\hline Statin & $16(89 \%)$ \\
\hline
\end{tabular}

Data are presented as mean (SD) [range] unless otherwise noted 


\section{Table 2. Hypotensive Response Monitoring $(n=18)$}

\begin{tabular}{|c|c|c|c|c|}
\hline & P30 & P60 & P120 & $p$ value \\
\hline Minimum HIIT systolic BP (mmHg) & $\begin{array}{c}137(126-148) \quad[104- \\
184]\end{array}$ & $\begin{array}{c}141(130-152)^{\mathrm{a}} \\
{[108-196]}\end{array}$ & $\begin{array}{c}131(121-141)^{b} \\
{[98-180]}\end{array}$ & 0.0189 \\
\hline Minimum HIIT systolic - resting BP & $19(8-31)$ & $23(12-34)^{\mathrm{a}}$ & $13(3-23)^{\mathrm{b}}$ & 0.0189 \\
\hline$(\mathrm{mmHg})$ & {$[-16$ to 56$]$} & {$[-12$ to 66$]$} & {$[-24$ to 50$]$} & \\
\hline $\begin{array}{l}\text { No. minimum HIIT systolic below } \\
\text { resting, } \mathrm{n}(\%)\end{array}$ & $5(28 \%)$ & $2(11 \%)$ & $5(28 \%)$ & 0.4330 \\
\hline $\begin{array}{l}\text { No. minimum HIIT systolic } 20 \\
\text { mmHg below resting, n (\%) }\end{array}$ & $0(0 \%)$ & $0(0 \%)$ & $1(6 \%)$ & 0.9995 \\
\hline $\begin{array}{l}\text { Minimum HIIT diastolic BP } \\
(\mathrm{mmHg})\end{array}$ & $\begin{array}{c}79(75-82) \\
{[60-90]}\end{array}$ & $\begin{array}{c}80(76-83) \\
{[64-90]}\end{array}$ & $\begin{array}{l}79(75-83) \\
{[68-100]}\end{array}$ & 0.7241 \\
\hline Minimum HIIT diastolic - resting & $5(-1-10)$ & $6(1-11)$ & $5(-1-11)$ & 0.7241 \\
\hline $\mathrm{BP}(\mathrm{mmHg})$ & {$[-12$ to 32$]$} & {$[-10$ to 32$]$} & [-10 to 32$]$ & \\
\hline $\begin{array}{l}\text { No. minimum HIIT diastolic below } \\
\text { resting, n (\%) }\end{array}$ & $4(22 \%)$ & $4(22 \%)$ & $8(44 \%)$ & 0.1969 \\
\hline Nausea, n (\%) & $0(0 \%)$ & $0(0 \%)$ & $0(0 \%)$ & 1.0000 \\
\hline Lightheadedness, n (\%) & $0(0 \%)$ & $1(6 \%)$ & $0(0 \%)$ & 0.9768 \\
\hline \multicolumn{5}{|c|}{$\begin{array}{l}\text { Data presented as mean ( } 95 \% \text { confidence interval) [range] unless otherwise noted; } p \text { values indicate significance of the overall } \\
\text { generalized linear mixed model. Pairwise comparisons between non-matching letters are significant at } p<.05 \text { using Tukey-Kram }\end{array}$} \\
\hline
\end{tabular}


Table 3. Orthopedic Safety Monitoring $(n=18)$

\begin{tabular}{lcccc}
\hline & P30 & P60 & P120 & p value \\
Falls, $\mathrm{n}(\%)$ & $0(0 \%)$ & $0(0 \%)$ & $0(0 \%)$ & 1.0000 \\
No. of subjects who engaged & $2(11 \%)$ & $3(17 \%)$ & $1(6 \%)$ & 0.4855 \\
harness at least one time (\%) & & & 4 & 0.7876 \\
$\quad$ Total no. of times engaged & 9 & 4 & $0(0 \%)$ & 1.0000 \\
New pain after exercise, $\mathrm{n}(\%)$ & $0(0 \%)$ & $0(0 \%)$ & & \\
\hline p values indicate significance of the overall generalized linear mixed model & & & \\
\hline
\end{tabular}


Table 4. Cardiovascular Intensity Peaks (n=18)

\begin{tabular}{|c|c|c|c|c|}
\hline & P30 & P60 & P120 & p value \\
\hline Max HR (bpm) & $\begin{array}{c}130(121-139)^{\mathrm{a}} \\
{[92-165]}\end{array}$ & $\begin{array}{c}127(117-137)^{\mathrm{a}} \\
{[77-161]}\end{array}$ & $\begin{array}{c}117(110-124)^{b} \\
{[83-135]}\end{array}$ & 0.0003 \\
\hline Max HR (\%Peak) & $\begin{array}{c}97(92-103)^{\mathrm{a}} \\
{[81-121]}\end{array}$ & $\begin{array}{c}95(90-101)^{\mathrm{a}} \\
{[69-108]}\end{array}$ & $\begin{array}{c}88(83-93)^{b} \\
{[73-101]}\end{array}$ & 0.0003 \\
\hline Max HR (\%AP-HR $\left.{ }_{\max }\right)$ & $\begin{array}{c}78(73-84)^{\mathrm{a}} \\
{[54-98]}\end{array}$ & $\begin{array}{c}77(71-83)^{\mathrm{a}} \\
{[45-99]}\end{array}$ & $\begin{array}{c}71(66-76)^{\mathrm{b}} \\
{[48-87]}\end{array}$ & 0.0003 \\
\hline No. over HR peak, n (\%) & $6(33 \%)$ & $8(44 \%)$ & $2(11 \%)$ & 0.1333 \\
\hline No. over AP-HR ${ }_{\max }, \mathrm{n}(\%)$ & $0(0 \%)$ & $0(0 \%)$ & $0(0 \%)$ & 1.0000 \\
\hline Max systolic BP (mmHg) & $\begin{array}{c}159(144-173) \\
{[120-210]}\end{array}$ & $\begin{array}{c}160(149-172)^{\mathrm{a}} \\
{[120-210]}\end{array}$ & $\begin{array}{c}149(138-160)^{\mathrm{b}} \\
{[120-200]}\end{array}$ & 0.0192 \\
\hline Max systolic BP (\%Peak) & $\begin{array}{c}97(90-104) \\
{[72-120]}\end{array}$ & $\begin{array}{c}99(92-105)^{\mathrm{a}} \\
{[78-127]}\end{array}$ & $\begin{array}{c}91(87-95)^{\mathrm{b}} \\
{[78-108]}\end{array}$ & 0.0177 \\
\hline Max diastolic BP $(\mathrm{mmHg})$ & $\begin{array}{c}88(84-93) \\
{[80-110]}\end{array}$ & $\begin{array}{c}86(81-90) \\
{[64-110]}\end{array}$ & $\begin{array}{c}87(82-91) \\
{[75-112]}\end{array}$ & 0.2251 \\
\hline Max diastolic BP (\%Peak) & $\begin{array}{c}100(93-107) \\
{[75-125]}\end{array}$ & $\begin{array}{c}97(91-104) \\
{[70-115]}\end{array}$ & $\begin{array}{c}98(93-104) \\
{[70-117]}\end{array}$ & 0.2220 \\
\hline \multicolumn{5}{|c|}{ Data presented as mean ( $95 \%$ confidence interval) [range] unless otherwise noted; $p$ values indicate significance of the overall } \\
\hline
\end{tabular}


Figure 1. Heart Rate Responses Relative to Peak HR from the Symptom-Limited Graded

Exercise Test $(\mathbf{n}=18)$. Each line represents an individual participant. The thick dashed horizontal line represents $\mathrm{HR}_{\text {peak }}$ from the graded exercise test. The dark colored lines are participants taking B-Blockers. HRR, heart rate reserve.

Figure 2. Heart Rate Responses Relative to Age-Predicted Maximal HR (n=18).

Each line represents an individual participant. The thick dashed horizontal line represents Agepredicted $\mathrm{HR}_{\max }$. The dark colored lines are participants taking B-Blockers. APmax-HRR, Agepredicted maximal heart rate reserve. 

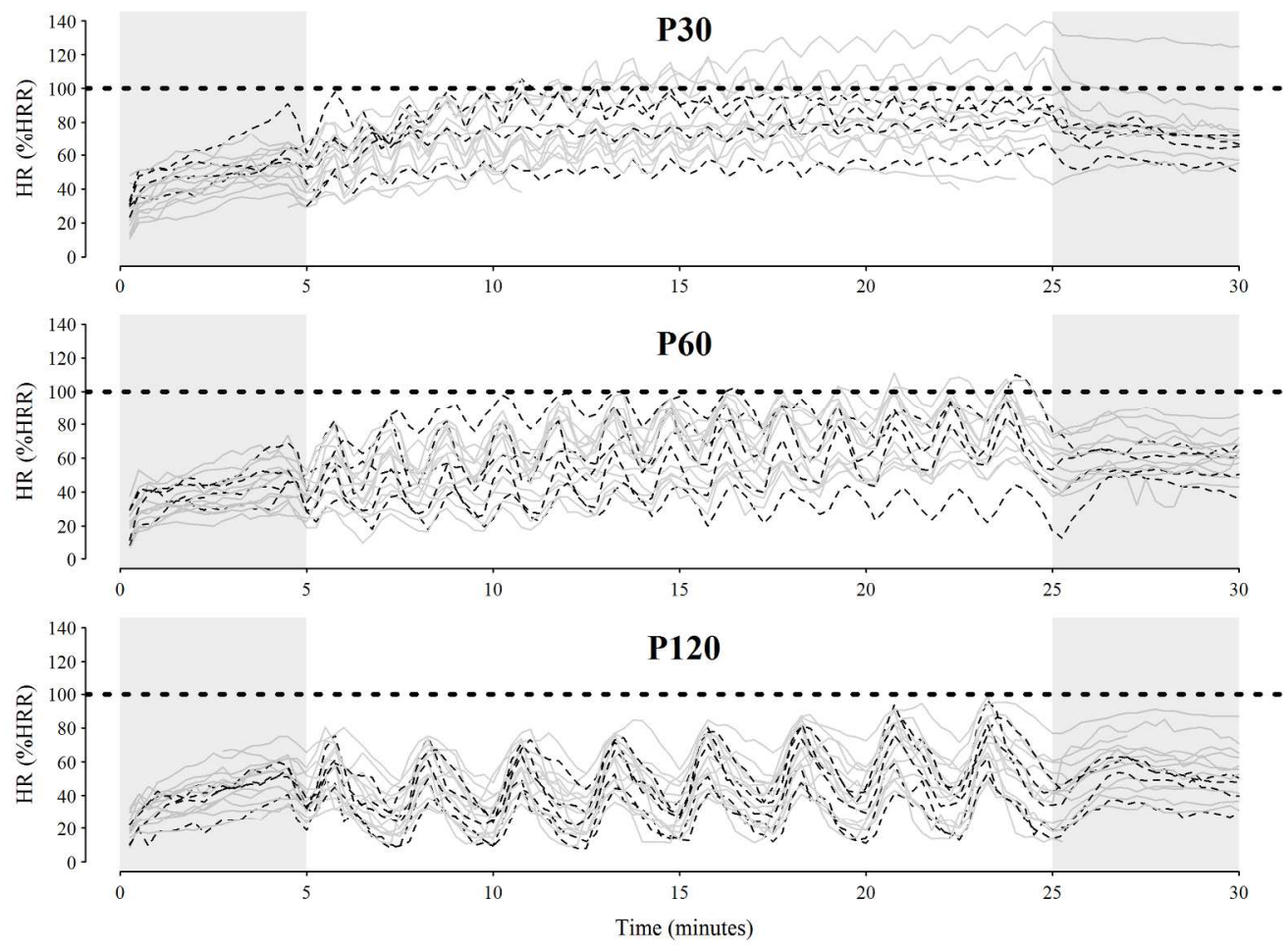

$203 \times 152 \mathrm{~mm}(300 \times 300 \mathrm{DPI})$ 

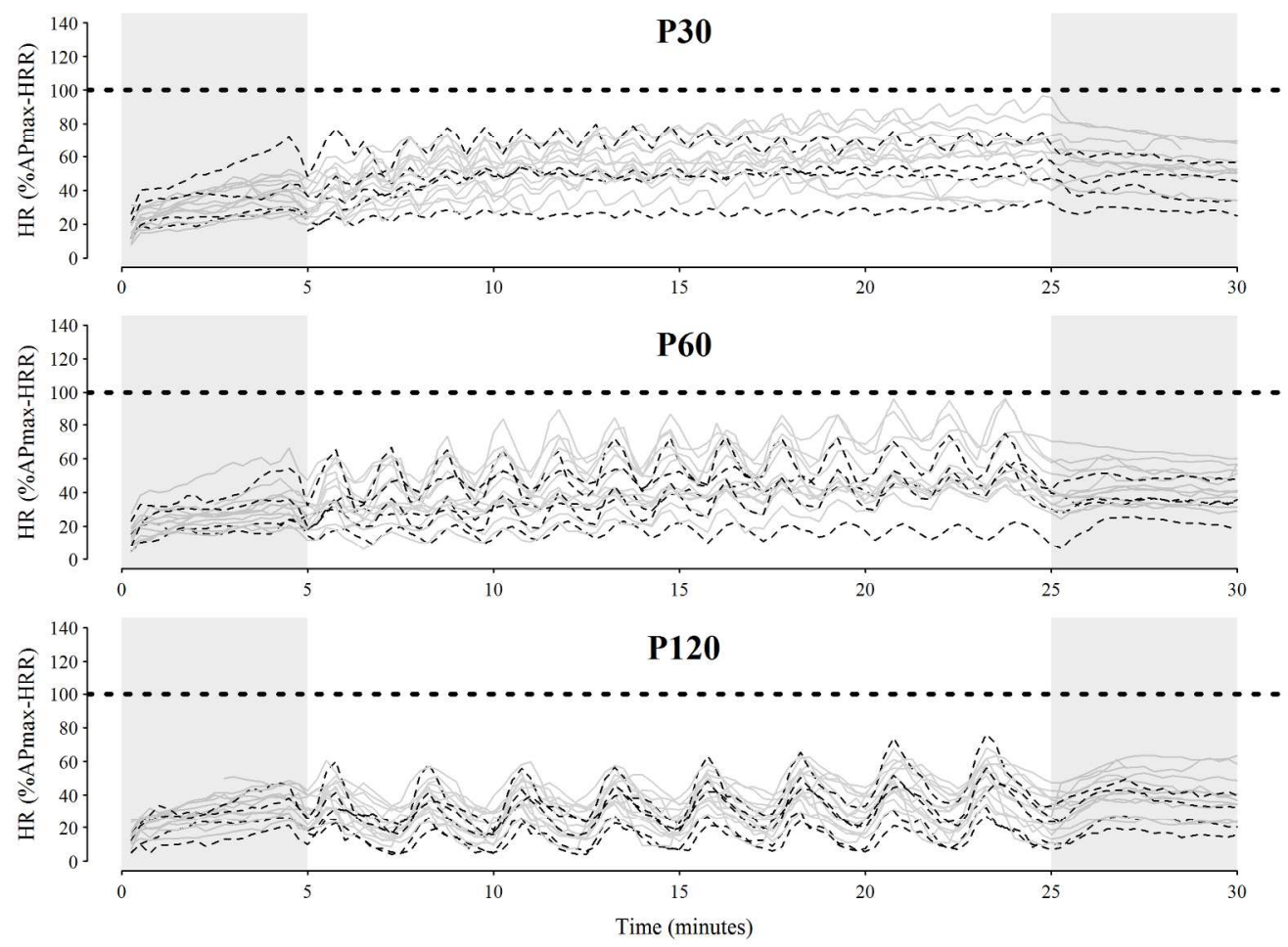

$203 \times 152 \mathrm{~mm}(300 \times 300$ DPI $)$ 